\title{
A NÃO-CIÊNCIA DE HUMANÓIDES E GOLFINHOS: VAN FRAASSEN E O CONCEITO DE COMUNIDADE EPISTÊMICA
}

\author{
Alessio Gava* \\ Universidade Estadual do Paraná (UNESPAR) - campus Apucarana \\ (D) http://orcid.org/0000-0002-0426-8392
}

\section{RESUMO:}

A noção de comunidade epistêmica é essencial para a caracterização da observabilidade, conceito-chave para o empirismo construtivo de Bas van Fraassen. Segundo o filósofo holandês, com efeito, observável seria uma abreviação de observável-para-nós. Neste trabalho será mostrado que a suposta rigididade do autor de $A$ Imagem Científica, o qual parece não estar disposto a admitir mudanças na composição da comunidade epistêmica (constituída, segundo ele, pela raça humana), é na verdade uma assunção de modéstia e de bom senso; trata-se do reconhecimento de que o empreendimento científico nada mais é do que uma atividade humana, entre muitas outras.

PALAVRAS-CHAVE: Van Fraassen; Observável; Observabilidade; Empirismo Construtivo; Comunidade epistêmica.

\section{HUMANOIDS AND DOLPHINS' NOT-SCIENCE: VAN FRAASSEN AND THE CONCEPT OF EPISTEMIC COMMUNITY}

\begin{abstract}
:
The notion of epistemic community is crucial for the characterization of observability, a cornerstone for Bas van Fraassen's constructive empiricism. As a matter of fact, observable is, to him, a short for observable-by-us. In this work, it will be shown that the alleged rigidity of the author of The Scientific Image, apparently not very keen to admitting changes in the epistemic

* Mestre e Doutor em Lógica e Filosofia da Ciência pela Universidade Federal de Minas Gerais (UFMG), Brasil. Professor da Universidade Estadual do Paraná (UNESPAR), campus Apucarana, Brasil. E-mail: alessiogava@yahoo.it

A não-ciência de humanóides e golfinhos: Van Fraassen e o conceito de comunidade epistêmica - Alessio Gava


community (constituted - according to him - by the human race), is actually an assumption of modesty and good judgment; it means recognizing that scientific enterprise is just a human activity, among many others.

KEYWORDS: Van Fraassen; Observable; Observability; Constructive empiricism; Epistemic community.

Em 2005, van Fraassen explicou da seguinte maneira o que significa aceitar uma teoria científica segundo os ditames do empirismo construtivo, a vertente filosófica antirrealista que propôs vinte e cinco anos antes em seu seminal livro The Scientific Image (1980): “O que as ciências falam acerca das partes observáveis do mundo é verdadeiro, o resto não interessa." (van Fraassen 2005, 111, tradução nossa)

O crucial atributo observável é, segundo ele, um termo indexical. Equivale, a saber, a observável-para-nós. ${ }^{1} \mathrm{Na}$ opinião do filósofo holandês, a observabilidade não é uma propriedade intrínseca dos fenômenos, mas é função, entre outras coisas, daquilo que consideramos ser a comunidade epistêmica. Desde a publicação de A Imagem Científica, van Fraassen defende que ela é constituída por nós seres humanos, coerentemente com sua visão geral de que a ciência nada mais é que um empreendimento humano e que, por conseguinte, manter um ponto de vista antropocêntrico é uma questão de bom senso e de modéstia, ao contrário do que dizem os autores realistas.

Esses últimos, que não aceitam que as limitações dos seres humanos desenvolvam um papel tão importante na construção e na avaliação de uma teoria científica, questionaram o conceito de comunidade epistêmica, atacando o antropocentrismo do empirismo construtivo seja diretamente como através das consequências de uma eventual mudança de tal conceito para a questão da observabilidade.

Em A Imagem Científica, van Fraassen já mostrou estar ciente de que, se a comunidade epistêmica sofresse algum tipo de mudança, pelo fato de a espécie humana ter mudado ou de outros seres animados terem sido contemplados como parte da comunidade, o conjunto de crenças acerca do mundo evidentemente mudaria. ${ }^{2}$ Mas isso não deve ser visto como uma crítica

1 “O que conta como um fenômeno observável é função do que é a comunidade epistêmica ((...) observável é observável-para-nós)" (VAN FRAASSEN 2007, 45). Em 2003, van Fraassen reiterou que observável "é uma abreviação ou uma elipse para 'observável para nós', onde 'nós' se refere à nossa comunidade epistêmica" (MONTON \& VAN FRAASSEN 2003, 411, tradução nossa).

${ }^{2}$ Esse argumento de van Fraassen pode ser considerado uma resposta direta a Grover Maxwell, que em seu famoso artigo de 1962, "The ontological status of theoretical entities", deteu-se sobre o que aconteceria à extensão do adjetivo observável se alguém se encontrasse sob efeito 
ao antirrealismo, diz o filósofo holandês, a não ser que se pense que a conduta epistêmica deveria manter-se inalterada independentemente da evidência acessível; o que significaria endossar um ceticismo extremo ou um ato de fé incondicionado com relação à ciência (cf. VAN FRAASSEN 2007, 44-45). O bom senso, diversamente, nos diz que ela é um produto da atividade humana, sujeita por isso a limitações e dependente do tão antropocêntrico conceito de observabilidade. Se esse mudasse, a ciência seria diferente.

Paul Churchland e Jeff Foss, escrevendo acerca de A Imagem Científica nos anos imediatamente seguintes à publicação do livro de van Fraassen, imaginaram situações extremas, como sociedades compostas por indivíduos para os quais nada fosse observável, ou totalmente cegos, ou, ao contrário, que conseguissem um alcance maior do que o nosso quanto à evidência direta acerca do mundo, como no caso de humanóides cujo olho esquerdo fosse na verdade um microscópio eletrônico (cf. CHURCHLAND 1985, $42-44$ e Foss 1984, 87-91). Podemos, eles se perguntaram, negar legitimidade à ciência desenvolvida por essas sociedades?

Em "Empiricism in the Philosophy of Science" (1985), van Fraassen respondeu a essa questão. Ele afirma que nossa avaliação acerca da fisiologia dos indivíduos imaginados por Churchland (ou Foss), baseia-se necessariamente em nossa ciência, que nos leva a considerá-los - ou não indicadores fiáveis da presença de determinados fenômenos. Em outras palavras, nossas crenças e opiniões, inclusive acerca da 'ciência' de seres nãohumanos, são determinadas "pela opinião que temos acerca da adequação empírica de nossa ciência - e a extensão de 'observável' permanece, ex hypothesi, inalterada” (VAN FRAASSEN 1985, 257, tradução nossa). ${ }^{3}$

Não ver isso e estabelecer a priori qual seria o alcance da evidência acessível para essas sociedades - assumindo, por exemplo, que para os individuos que as compõem o DNA seria observável - significa assumir o papel de espectador onisciente, enquanto, evidentemente, nós não podemos ter um ponto de vista 'divino' que nos permita julgar a veracidade do que acontece de fato - nem com relação a nós mesmos e à nossa ciência. $\mathrm{O}$ argumento de Churchland é assim falacioso, pois ele assume como verdadeiro a priori o que está, justamente, em questão. ${ }^{4}$

de uma droga que 'ampliasse os limites da percepção' ou se nos deparássemos com um mutante que conseguisse enxergar os raios X (cf. MAXWELL 1962, 10-11). Situações similares foram propostas nas décadas seguintes por outros autores, como veremos, apesar das respostas de van Fraassen de 1980 e de 1985 , que nos parecem satisfatórias.

${ }^{3} \mathrm{O}$ argumento é reproposto praticamente com as mesma palavras no prefácio à edição italiana de The Scientific Image, publicada no mesmo ano.

${ }^{4}$ Essa questão é retomada e bem explicada por Filip Buekens, que considera satisfatória a resposta de van Fraassen a Churchland (cf. BUEKENS 1999, 23). 
Uma resposta direta a Foss veio de Warren Bourgeois em 1987, em um artigo bastante polêmico, no qual esse rebate uma por uma as críticas de Foss a van Fraassen e o acusa de não ter entendido a proposta filosófica do autor de $A$ Imagem Científica. Com relação à noção de comunidade epistêmica, em particular, Bourgeois afirma não haver nenhuma dificuldade para o empirista construtivo admitir que uma comunidade contemple tanto pessoas com visão normal quanto pessoas cegas, contrariamente ao que Foss pensa, pois essas últimas poderiam muito bem acreditar na existência de cores e a justificação disso repousaria no simples fato de elas fazerem parte de uma comunidade em que há membros que conseguem enxergar as cores das coisas. "É óbvio que diferentes membros de uma determinada comunidade terão diferentes capacidades de observar - escreve Bourgeois -, mas observabilidade para um é observabilidade para todos" (BOURGEOIS 1987, 307, tradução nossa).

A atribuição da propriedade de 'ser observável' a um dado fenômeno não é o fruto de um consenso entre os membros da comunidade ou resultado de um debate para decidir acerca dessa atribuição. Basta que pelo menos um membro tenha observado (ou seja capaz de observar) tal fenômeno para que ele seja considerado observável para a comunidade como um todo. Isso já podia ser depreendido de uma atenta leitura de A Imagem Científica $^{5}$ e foi reafirmado de forma que não deixa dúvidas, por van Fraassen, em 1992:

O termo 'observável' é muito parecido com outros termos comuns como 'portátil' e 'frágil'. Eles são, por assim dizer, termos antropocêntricos, pois se referem a nossas limitações. Eles não são pessoa-cêntricos, porém; computadores laptop são portáteis e copos de vinho frágeis, mesmo que algumas pessoas sejam demasiado fracas para carregá-los ou até quebrá-los (p. 13, tradução nossa).

Ademais, afirmar de maneira inequívoca que observável é uma abreviação para observável-para-nós, como faz van Fraassen, lhe permite equiparar a observação com um ato de detecção sem que ninguém possa sentirse legitimado a dizer que, segundo a caracterização dele, um termômetro 'observou' que hoje a temperatura é de $27^{\circ} \mathrm{C}$. Implícita na caracterização, mas mesmo assim bem clara, está a ideia de que o agente da observação é um membro da comunidade epistêmica - que não inclui termômetros, evidentemente. Nas palavras de William Seager:

\footnotetext{
${ }^{5}$ Cf. van Fraassen 1980, cap. 2, § 2. Em 1991, Foss publicou uma contrarréplica a Bourgeois, mas nela o conceito de comunidade epistêmica não é mais mencionado, o que faz supor que Foss considerou satisfatória a explicação de Bourgeois pelo que diz respeito a tal noção (cf. FOSS 1991).
} 
Uma observação é uma detecção acompanhada por uma classificação ativa e, tipicamente, por uma sucessiva formação de opinião. (...) Esse adendo crucial à noção de observação pode ser resumida no lema: observadores são acreditadores em potência. Isso marca a diferença entre meros mecanismos de detecção e observadores (SEAGER 1988, 181, tradução nossa). ${ }^{6}$

No mesmo artigo, inteiramente dedicado à noção de comunidade epistêmica, há uma passagem que também poderia servir como resposta a Foss e que esclarece ainda mais o "observabilidade para um é observabilidade para todos" de Bourgeois. Afirma Seager:

os membros de uma comunidade epistêmica devem cada um respeitar as capacidades epistêmicas do outro. Em segundo lugar, as crenças de um outro membro da mesma comunidade garantem a crença (...) de cada membro. Tais crenças representam uma parte da imagem do mundo que nós almejamos desenhar, mas que, graças ao esforço de outros, não precisamos desenhar sozinhos (SEAGER 1988,184 , tradução nossa). ${ }^{7}$

Analisando os exemplos propostos por Maxwell, Churchland e Foss, e a posição de van Fraassen, André Kukla conclui que o filósofo holandês, se quiser evitar o colapso de sua posição antirrealista, está condenado a

não admitir nenhuma flexibilidade na composição da comunidade epistêmica. Se você está dentro, está dentro, e se você está fora, você continuará fora, aconteça o que acontecer. Essa é a única maneira de garantir que sempre haverá uma classe de sentenças nas quais nunca será possível acreditar, independentemente do que acontecerá no futuro (KUKLA 1996, 208, tradução nossa).

Qualquer inclusão de seres com capacidades perceptivas diferentes da nossa, diz Kukla, seria "o primeiro passo de uma slippery slope" (207, tradução nossa) na qual qualquer entidade inobservável postulada por uma teoria científica aceita poderia um dia tornar-se observável. Segundo Kukla, van Fraassen fornece um outro argumento que corrobora a ideia segundo a qual a comunidade epistêmica não pode sofrer nenhum tipo de alteração: trata-se daquele citado, apresentado em "Empiricism in the Philosophy of Science",

${ }^{6}$ Considerações análogas levaram Buekens a considerar a observação como uma ação intencional e a cunhar o lema "observar em um espaço de razões" (cf. BUEKENS 1999).

7 Surpreendentemente, Seager prossegue o artigo imaginando a inclusão na comunidade epistêmica de máquinas com inteligência artificial, repropondo, mutatis mutandis, o mesmo argumento realista de Churchland e Foss. Para ele continua valendo, sem dúvida, a resposta de van Fraassen de 1985. 
segundo o qual o máximo que poderíamos conceder a outros seres é de considerá-los indicadores fiáveis de um determinado fenômeno, exatamente como se fossem apenas um instrumento. Dessa maneira, afirma Kukla, "nunca encontraremos motivos que nos compelam racionalmente a ampliar nossa comunidade epistêmica. Não há nenhuma dúvida, portanto, que o antirrealista deve ser inflexível acerca de quem entra no círculo epistêmico" (209, tradução nossa).

Mas uma atitude tão radical, na opinião do filósofo canadense, deveria encontrar suporte em algum critério epistêmico forte. No entanto, parece não haver nenhum. Ademais, Kukla considera que um dos experimentos mentais conduzidos por Churchland constitui de fato uma dificuldade insuperável para van Fraassen. Em "Empiricism in the Philosophy of Science", contudo, van Fraassen dispensou tal argumento, achando que bastasse uma única resposta para todos os 'experimentos' de Churchland.

A situação imaginada por Churchland é aquela de uma comunidade epistêmica constituída por seres humanos cujos aparatos sensoriais tenham sido completamente substituídos por próteses eletrônicas. Nesse caso, diz Kukla, a questão não é que não estamos em condição de estabelecer se a 'ciência' deles é ciência assim como nós a entendemos. Simplesmente, seguindo van Fraassen, tais seres não poderiam ter uma ciência.

Mas se as próteses fossem, do ponto de vista do funcionamento, completamente idénticas aos órgãos que elas estão substituindo, esses seres seriam computacionalmente equivalentes a nós; haveria "um isomorfismo entre as relações de input-output que os caracterizam e aqueles que caracterizam a nós" (KUKLA 1996, 212, tradução nossa).

O produto disso, conclui Kukla, seria uma ciência indistinguível da nossa. Ainda assim, ela deveria ser dispensada? Não deveria ser considerar ciencia? A única saída para evitar responder negativamente a essas perguntas, diz o filósofo canadense, é abandonar o critério segundo o qual observação é detecção sem o auxílio de instrumentos. Diferentemente, o antirrealismo (de van Fraassen) seria dificilmente defensável.

Em 2005, porém, van Fraassen parece ter respondido definitivamente à questão da 'observação' com a ajuda de instrumentos com poucas e eficazes palavras:

O que eu entendo com 'observável' aqui é somente aquilo que é acessível aos sentidos humanos sem ajuda. O termo 'observável' é como 'quebrável' e 'portátil'. Eu não chamaria esse prédio ou a locomotiva de um trem de quebráveis somente porque nós agora temos instrumentos que podem quebrá-los - nem chamaria um tanque de guerra de portátil porque ele pode ser transportado por um avião de transporte Hércules. Da mesma maneira, o termo 
'observável' não se estende ao que, supostamente, é detectado por meio de instrumentos (VAN FRAASSEN 2005, 112, tradução nossa).

Todavia, ele prossegue, não é somente nossa tecnologia que muda, nós mesmos mudamos. A evolução de nossa espécie não chegou a um fim.

Como lidar com isso? E se o próprio van Fraassen admite que, se nós fôssemos diferentes, a extensão do termo 'observável' também seria diferente, por que não mudar tal extensão agora mesmo?

Retomando e aprofundando algo que já tinha escrito em 1985, o filósofo holandês afirma que esse argumento realista, que ataca um aspecto importante da observabilidade, tem a forma a seguir:

1) Nós somos ou poderíamos nos tornar $X$.

2) Se nós fôssemos $X$, então poderíamos observar $Y$.

3) Nós somos, de fato, em determinadas condições realizáveis, como $X$ sob todos os aspectos relevantes.

4) Aquilo que nós poderíamos observar em condições realizáveis, é observável.

Logo: Y é observável (van Fraassen 2005, 114, tradução nossa).

Esse argumento modal aparentemente é válido, segundo confirma van Fraassen. Todavia, na premissa dois, há implícito algo que um empirista construtivo pode no máximo aceitar, mas não acreditar. Com efeito, se Y é, atualmente, uma entidade inobservável postulada por uma teoria científica aceita, um empirista construtivo aceita a premissa em questão, mas certamente não acredita nela, em se tratando de uma afirmação não-empírica. ${ }^{8}$ Para acreditar nela (ou rejeitá-la definitivamente), deveríamos assumir um ponto de vista 'divino', externo, o que está fora das possibilidades humanas. Nem a premissa três escapa da mesma objeção, conforme van Fraassen mostra (cf. 2005, 115-117).

$\mathrm{O}$ argumento modal com o qual podem ser esquematizados os experimentos mentais de Maxwell, Churchland e Foss, e que está implícito em todos eles, não afeta portanto o empirismo construtivo e a dicotomia sobre a qual ele repousa.

Uma atenção especial, todavia, van Fraassen dedica ao artigo de Seager de 1988, propondo ele mesmo, como experimento mental, de imaginarmos que um dia os golfinhos - dos quais sempre escutamos dizer que são animais muito inteligentes - serão admitidos como membros de nossa comunidade epistêmica. Se nossa ciência nos dissesse que a entidade inobservável (para nós humanos)

\footnotetext{
${ }^{8} \mathrm{Um}$ empirista construtivo acredita na verdade de todas as proposições empíricas de teorias aceitas e permanece neutro com relação a todas as proposições não-empíricas das mesma teorias ('empírica' seria uma proposição acerca de objetos reais e observáveis). Essa é, segundo F. A. Muller, a epistemic policy do empirismo construtivo (cf. MULLER 2004).
} 
$\mathrm{Y}$ existe e que os golfinhos podem 'observar' $\mathrm{Y}$, qual deveria ser nossa postura? Nos dias anteriores à data em que os golfinhos tornarão-se membros oficiais de nossa comunidade epistêmica, não deveríamos desistir de nosso agnosticismo (ou ateísmo) e admitir Y como observável?

"Se nós estamos certos de que no futuro teremos uma determinada opinião, então deveríamos tê-la agora mesmo - sob pena de incoerência", diz van Fraassen $(2005,127$, tradução nossa). Mas não é esse o caso, no exemplo dos golfinhos. Antes da admissão deles na nossa comunidade epistêmica, nós éramos agnósticos acerca da existência do inobservável (para nós) Y. Portanto, não tínhamos a crença de que os golfinhos podem observar Y. Tudo que podemos dizer, antes da data de admissão, portanto, é que depois que 'eles' serão parte de 'nós', nossa opinião comum será inicialmente vaga, podendo variar entre os dois extremos "Y é inobservável" e "Y é observável". Em seguida, como resultado de uma epistemic policy comum, a opinião deveria convergir em direção àquela que um dos dois grupos - os humanos ou os golfinhos - tinha antes da união, com base na evidência disponível. Mas chegar a uma conclusão agora seria incoerente e irracional (cf. VAN FRAASSEN 2005, 130-131).

Frente a tudo isso, manter um ponto de vista 'antropocêntrico' parece ser deveras uma questão de bom senso e de modéstia, pois a ciência nada mais é do que um empreendimento humano, como muitos outros. O antropocentrismo do empirismo construtivo de van Fraassen pode assim ser visto como uma sorte de "humanismo, ou seja, o reconhecimento de que não podemos, e não deveríamos tentar de, escapar de nós mesmos" (CHANG 2004, 889, tradução nossa). A comunidade epistêmica não pode ser outra coisa, enfim, senão a própria raça humana, exatamente como van Fraassen sempre defendeu. 


\section{Referências bibliográficas}

BOURGEOIS, Warren. Discussion: on rejecting Foss's image of Van Fraassen. Philosophy of Science, s.1., v. 54, n. 2, p. 303-308, jun. 1987.

BUEKENS, Filip. Observing in a space of reasons. http://drcwww.uvt.nl/ buekens/obs.doc. Último acesso em: 11 jun. 2007.

CHANG, Hasok. A case for old-fashioned observability, and a reconstructed Constructive Empiricism. In: Proceedings Philosophy of Science Association $19^{\text {th }}$ Biennial Meeting - PSA 2004: PSA 2004 Contributed Papers, Austin, p. 876-887, 2004.

CHURCHLAND, Paul M. The Anti-Realist Epistemology of van Fraassen's The Scientific Image. Pacific Philosophical Quarterly, s.1., n.63, jul. 1982.

. The ontological status of observables: in praise of the superempirical virtues. In: CHURCHLAND, P. M.; HOOKER, C. A. (eds.), Images of Science. Essays on Realism and Empiricism, with a Reply form Bas C. van Fraassen. Chicago: The University of Chicago Press, 1985, p. 35-47.

FOSS, Jeff. On accepting Van Fraassen's image of science. Philosophy of Science, s.1., v. 51, n. 1, p. 79-92, mar. 1984.

. Discussion: on saving the phenomena and the mice: a reply to Bourgeois concerning Van Fraassen's image of science. Philosophy of Science, s.1., v. 58, n. 2, p. 278-287, jun. 1991.

FRAASSEN, Bas C. Van. The Scientific Image. Oxford: Oxford University Press, 1980.

- A Imagem Científica. Trad. de Luiz Henrique de Araújo Dutra. São Paulo: Editora UNESP / Discurso Editorial, 2007.

. Prefazione all'edizione italiana. Trad. de Roberto Festa. In: L'immagine scientifica. Bologna: Editrice CLUEB, 1985.

Preface to the Greek edition. http://www.princeton.edu/ fraassen/SciImg/Sci_ImagePrefaceGreek.pdf. Último acesso em: 11 jun. 2007.

. Empiricism in the Philosophy of Science. In: CHURCHLAND, P. M.; HOOKER, C. A. (eds.), Images of Science. Essays on Realism and Empiricism, with a Reply form Bas $C$. van Fraassen. Chicago: The University of Chicago Press, 1985, p. 245-308.

. From vicious circle to infinite regress, and back again. Philosophy of

Science Association Proceedings, s.1., v. 2, p. 6-29, 1992.

. The day of the dolphins. Puzzling over epistemic partnership. In:

IRVINE, A.; PEACOCK, K. (eds.), Mistakes of Reason: Essays in Honour of John Woods. Toronto: University of Toronto Press, 2005, p. 111-133.

KUKLA, André. The Theory-Observation Distinction. The Philosophical Review, s.1., v. 105, n. 2, p. 173-230, abr. 1996. 
. Studies in scientific realism. Oxford: Oxford University Press, 1998.

MAXWELL, Grover. The ontological status of theoretical entities. Minnesota Studies in the Philosophy of Science, 3, Minneapolis: University of Minnesota Press, 1962, p. 3-27.

MONTON, Bradley; FRAASSEN, Bas C. Van. Constructive Empiricism and Modal Nominalism. British Journal for the Philosophy of Science, s.1., n. 54, p. 405-422, 2003.

MULLER, Fred A. 2004. Can a Constructive Empiricist adopt the concept of observability? Philosophy of Science, s.1., n.71, p. 637-654, out. 2004.

SEAGER, William. Scientific Anti-Realism and the Epistemic Community. PSA: Proceedings of the Biennial Meeting of the Philosophy of Science Associati

Autor(a) para correspondência: Alessio Gava, Universidade Estadual do Paraná, Av. Minas Gerais, 5021, Núcleo Hab. Adriano Correia, CEP 86813-250, Apucarana - PR, Brasil. alessiogava@yahoo.it 